\title{
Phase Transformation of Mg-Calcite to Aragonite in Active-forming Hot Spring Travertines
}

\author{
Heather F. Greer, ${ }^{a}$ Wuzong Zhou ${ }^{*} a$ and Li Guo ${ }^{b}$ \\ ${ }^{a}$ EaStChem, School of Chemistry, University of St Andrews, Fife, KY16 9ST, United \\ Kingdom, E-mail: wzhou@st-andrews.ac.uk; Fax: +44 1334 463808; Tel: +44 1334 \\ 467276 \\ ${ }^{b}$ CASP, Department of Earth Sciences, University of Cambridge, West Building, 181a \\ Huntingdon Road, Cambridge, CB3 0DH, United Kingdom.
}

\begin{abstract}
A travertine specimen collected from the western part of Yunnan Province of China was subjected to microstructural analysis by powder X-ray diffraction, scanning electron microscopy, high resolution transmission electron microscopy and energy dispersive X-ray spectroscopy. A new formation mechanism was proposed whereby polycrystalline rhombohedral particles of magnesium-containing calcite underwent a phase transformation into sheaf-like clusters of aragonite microrods. It is proposed that a high concentration of magnesium ions and embedded biological matter poisoned the growth of calcite and therefore instigated the phase transformation of the core of the rhombohedral calcite particles to an aragonite phase with a higher crystallinity. The single crystalline aragonite microrods with a higher density than the Mg-calcite nanocrystallites grew at the expense of the latter to generate sheaf-like clusters. This newly discovered formation mechanism is expected to enhance previous knowledge on this geologically important phase transformation from a morphology point of view.
\end{abstract}




\section{Introduction}

Travertine is a $\mathrm{CaCO}_{3}$ deposit precipitated from mineral springs, especially hot springs. Travertine primarily forms through the transfer of carbon dioxide from ground water highly charged with calcium and bicarbonate (Capezzuoli et al. 2014). Rapid degassing occurs when the water meets the atmosphere and subsequently cools. This causes the precipitation of $\mathrm{CaCO}_{3}$ at the vent of a hot spring (Pentecost 2005). Calcium carbonate precipitates as one of three anhydrous polymorphs, calcite, vaterite and aragonite. Phase diagrams have proven that calcite is the most thermodynamically stable whilst vaterite is the least (Kawano et al. 2009). Several factors such as supersaturation, $\mathrm{pH}$, temperature, the presence of metal ions or organic matter are well known to have a strong influence on which polymorph is obtained (Jin et al. 2011; Han et al. 2006). Travertine deposits typically consist of calcite with variably forms of aragonite that have been reported to be preferentially precipitated at higher temperatures (Pentecost 2005). Phase transformation from aragonite to calcite following an interface-coupled dissolution-reprecipitation mechanism has been extensively studied (Perdikouri, et al., 2013). Alternatively, in the presence of a high concentration of magnesium

(typically above $\sim 10 \mathrm{mmol} \mathrm{L}^{-1}$ ) aragonite can form at room temperature (Pentecost 2005; Arp et al. 2001). It is noted that the internal energy change in the conversion of pure-phase calcite to aragonite is only $\pm 0.21 \mathrm{~kJ} / \mathrm{mol}$ (Atkins and De Paula 2010).

Travertine deposits almost always contain a small amount of embedded organic matter (Pentecost 2005). The precipitation of $\mathrm{CaCO}_{3}$ in travertine is strongly related to the nucleation in a microbial biofilm. Bioactivities of the microbial biofilm were found to be crucial, as absence of the biofilm has been known to prevent the precipitation of $\mathrm{CaCO}_{3}$ (Plee et al. 2008). The biofilm consisting of negatively charged extracellular polymeric substances (EPS) is known to preferentially induce the nucleation and precipitation of calcite by binding to the surface of $\mathrm{Ca}^{2+}$ (Arp et al. 2001). The microbial biofilm in travertine is an aggregate of bacteria, algae, fungi and protozoa (Vu et al. 2009). These microorganisms are embedded in their self-produced matrix of EPS. EPS not only protects the cells but also facilitates communication between cells through cell-cell recognition (Jones and Renaut 2008). EPS is typically high molecular weight biopolymers primarily consisting of polysaccharides, as well as small quantities of proteins, nucleic acids and lipids. The composition of EPS will vary greatly depending on the type of microorganisms and the environmental conditions under which the biofilms exist. Since the major proportion of EPS is protein, the isoelectric point of EPS is always in the acidic $\mathrm{pH}$ range (Pentecost 1985). Although the exact isoelectric point of 
EPS is unique to the conditions of each individual system, values in the range of 1.6-2.8 have been reported several times (Yuan and Wang 2013; Ruan 2013).

Although travertines have been studied for more than a century, information regarding the microstructures of carbonate minerals in travertines and their formation mechanism is limited. One explanation for this is that usually only the surface of travertine specimens are studied using scanning electron microscopy (SEM). This has provided very limited information on their inner structures. Therefore, in the present work, high resolution transmission electron microscopy (HRTEM) investigations were carried out on a travertine crust specimen in order to reveal the microstructures at atomic resolution.

We report herein the structural characterisation of a travertine specimen followed by a proposed formation mechanism. By collecting a profile across several layers of the travertine specimen, minerals could be identified at various stages of growth. A multi-step evolution from polycrystalline rhombohedral particles to single crystal-like rods arranged into sheaves was observed as associated with a phase transformation from Mg-calcite to aragonite. Although this geologically important phase transformation from $\mathrm{Mg}$-calcite to aragonite is a relatively common occurrence in nature it is usually simulated in the laboratory (Hacker et al. 1992, 2005; Lin and Huang 2004). Despite this, the step-by-step transformation is not usually studied from a morphology point of view. Understanding the inhibitory effect $\mathrm{Mg}^{2+}$ has on the precipitation of calcium carbonates is one of the important issues remaining in biomineralisation research.

\section{Experimental}

Collection of travertine crust specimen: The travertine sample was collected from Shiqiang in the western part of Yunnan, China, where active travertine deposition is taking place along the edge of a small artificial pond. The sampled travertine is from the pond edge, representing deep green, millimeter-thick microbial mats.

Specimen characterisation: Powder X-ray diffraction (XRD) was performed on a PANalytical Empyrean diffractometer, using $\mathrm{Cu} \mathrm{K \alpha}$ radiation $(\lambda=1.5418 \AA)$. A scan rate of $0.92^{\circ} / \mathrm{min}$ was used. Analysis of the powder XRD patterns was carried out using Highscore plus software. SEM images of the specimens were obtained using a JEOL JSM-6700F fieldemission gun microscope, operating at 1 to $5 \mathrm{kV}$ with gentle mode. The travertine sample was prepared for SEM characterisation by lightly crushing in a pestle and mortar. Travertine segments with a dimension of several mm were placed a sticky carbon tab mounted on a brass stub. To overcome beam charging problems, the specimen surface was coated with a 
thin gold film. The FEG-SEM is equipped with an Oxford INCA system for energy dispersive X-ray spectroscopy (EDX), which was applied for examination of the chemical compositions of the specimens. Transmission electron microscopic (TEM) images were attained using a JEOL JEM-2011 electron microscope operating at an accelerating voltage of $200 \mathrm{kV}$. This electron microscope is also equipped with an Oxford Link ISIS SemiSTEM EDX system. The TEM and HRTEM images were recorded using a Gatan 794 CCD camera. For TEM sample preparation the travertine specimen was lightly ground with a pestle and mortar and suspended in acetone. One drop of the suspension was deposited onto a $3 \mathrm{~mm}$ sized copper grid with a thin holey carbon support film coating. The solvent was allowed to evaporate then the grid was placed in the specimen holder.

\section{Results and Discussion}

XRD was carried out on the travertine specimen (Figure 1) to determine if it is multiphasic. The XRD pattern in Figure 2 indicates the travertine specimen can be indexed to two highly crystalline phases, orthorhombic aragonite with the unit cell parameters of $a=$ 4.96, $b=7.96, c=5.74 \AA$, space group Pmon (JCPDS 41-1475) and rhombohedral magnesium calcite, $\mathrm{Mg}_{\mathrm{x}} \mathrm{Ca}_{1-\mathrm{x}} \mathrm{CO}_{3}$. Although the exact chemical formula of magnesium calcite is unknown, the XRD pattern of the travertine specimen confirms the unit cell parameters are slightly reduced compared to calcite $\left(\mathrm{CaCO}_{3}\right)$ where $a=4.9896, c=17.061 \AA$, space group $\mathrm{R} \overline{3} \mathrm{c}$ (JCPDS 47-1743). The reflection located at $26.7^{\circ}$ in Figure 2 is likely due to an impurity since it cannot be indexed to either $\mathrm{Mg}$-calcite or aragonite phases. The mean crystallite size of magnesium calcite and aragonite was calculated using the Scherrer equation. The crystallite size calculated from the (104) reflection of calcite is ca. $38 \mathrm{~nm}$ whereas that calculated from the (111) reflection of aragonite is $c a .60 \mathrm{~nm}$. 


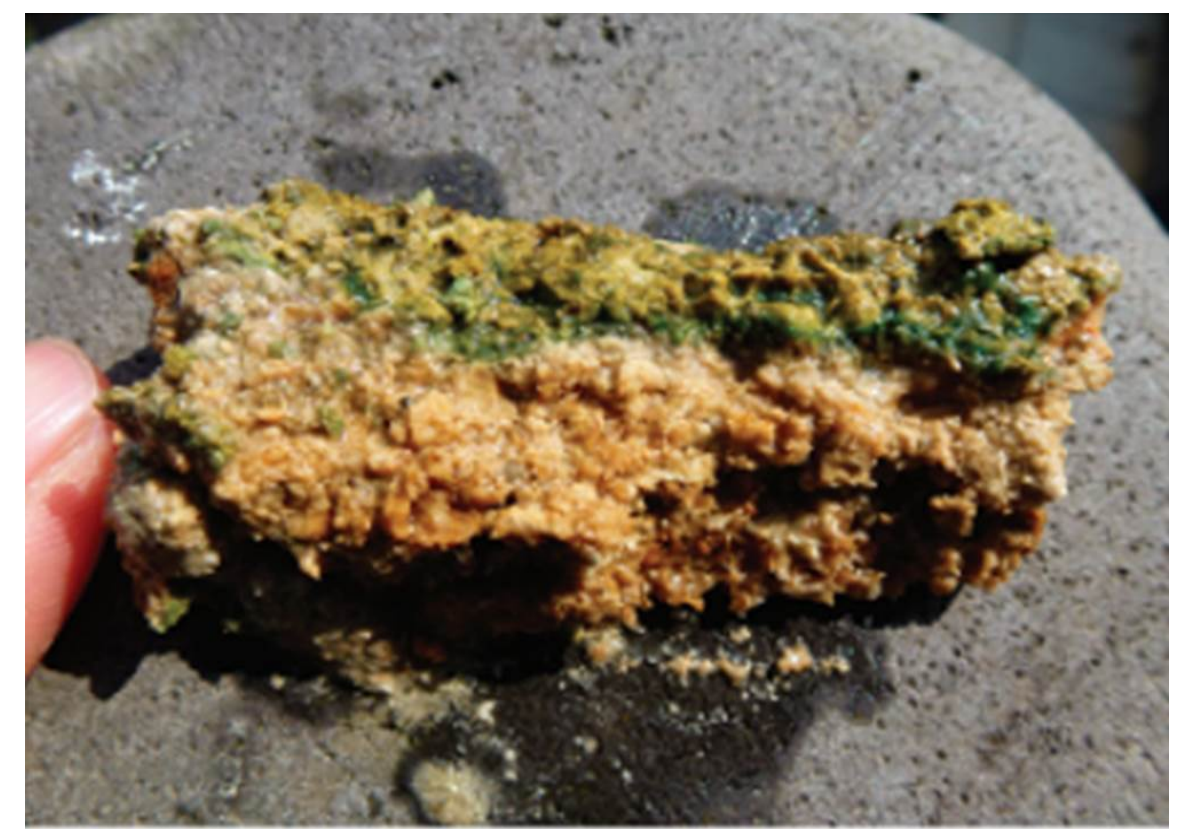

Figure 1. Photograph of the travertine specimen.

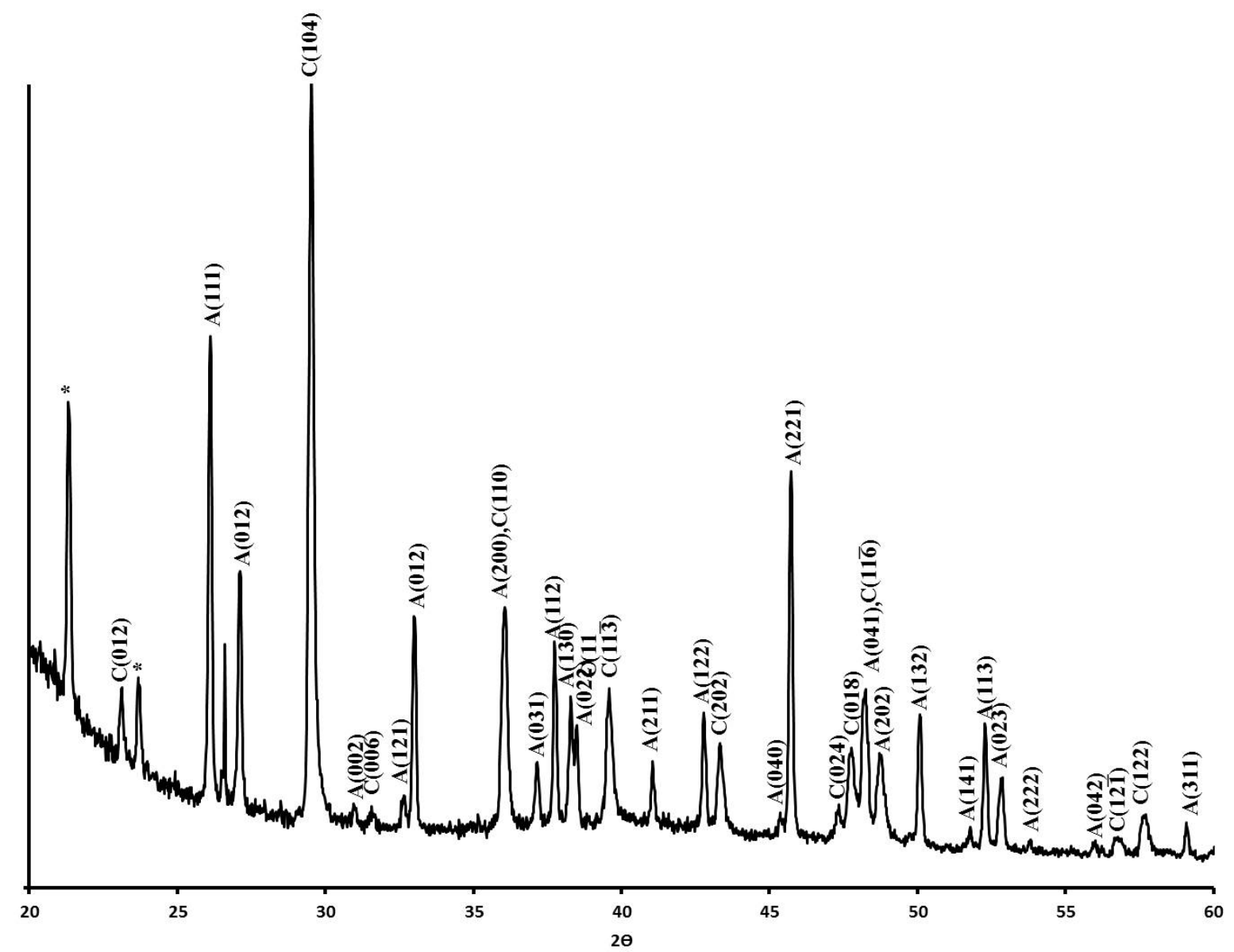

Figure 2. XRD pattern of travertine crust specimen which is indexed to rhombohedral magnesium calcite (C) and orthorhombic aragonite (A) phases. The peaks located at $21.4^{\circ}$ and $23.5^{\circ}$ (marked by *) correspond to columnar peaks from the diffractometer. 
The low magnification SEM image in Figure 3a shows that the calcite and aragonite phases can be easily distinguished. Particles displaying a rhombohedral type habit are characteristic of calcite whilst the microrod morphology is typical of aragonite. This has also been confirmed by HRTEM (see below). Higher magnification SEM images (Figure 3b,c) of the two morphologies show the rhombohedral calcite particles have a dimension of 30-40 $\mu \mathrm{m}$ whilst the aragonite microrods have a long dimension of 20-30 $\mu \mathrm{m}$ and a short dimension of $\sim 3 \mu \mathrm{m}$. EDX analysis (Figure 3d) of rhombohedral calcite particles detected $\mathrm{Mg}, \mathrm{Ca}, \mathrm{C}$ and $\mathrm{O}$ whilst EDX (Figure 3e) of aragonite microrods detected $\mathrm{Ca}, \mathrm{C}$ and $\mathrm{O}$. The $\mathrm{Au}$ peaks in both EDX spectrums are from the coating applied to the surface of the specimens to reduce the charging effects.
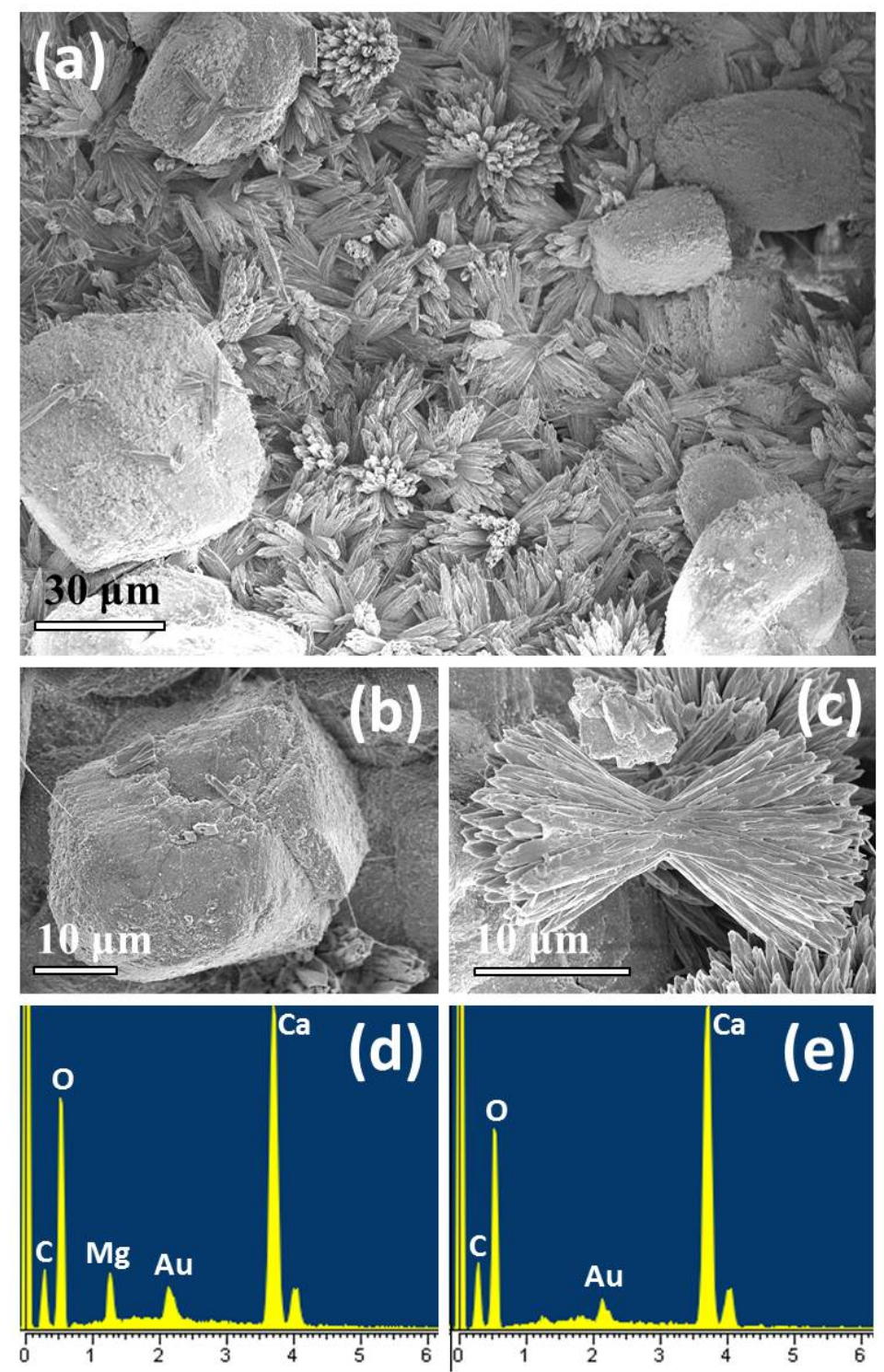

Figure 3. (a) Low magnification SEM image showing two distinct morphologies, rhombohedral calcite and aragonite rods. Higher magnification SEM image and corresponding EDX spectra of $(b, d)$ rhombohedral calcite and $(\mathrm{c}, \mathrm{e})$ aragonite microrods. 

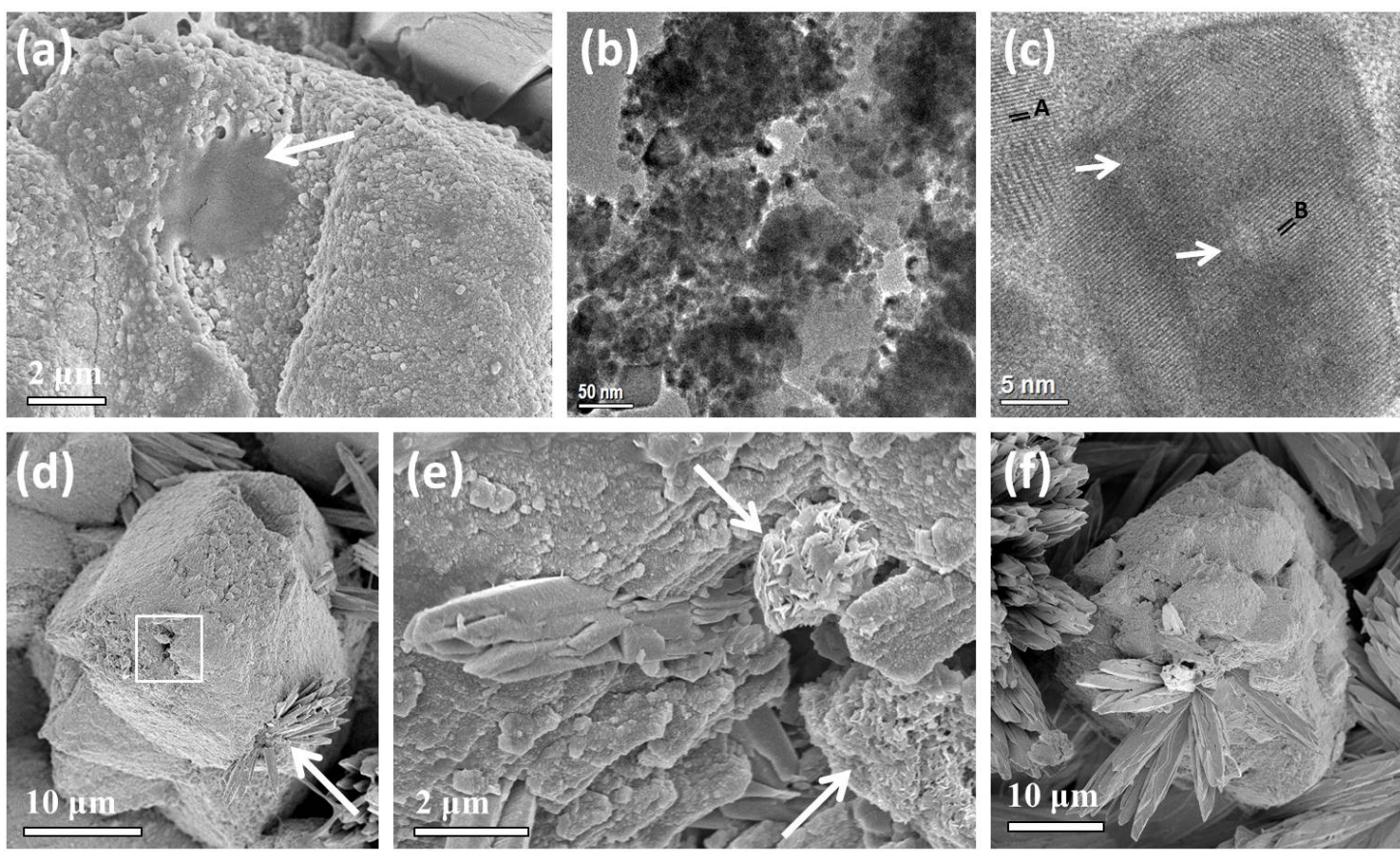

Figure 4. (a) High resolution SEM image of the surface of a rhombohedral magnesium calcite particle. The arrow marks a smooth region which is likely an area containing a high concentration of EPS molecules. (b) TEM image of magnesium calcite aggregates with a size of 10-50 nm. (c) HRTEM image of a selected area in (b) showing individual magnesium calcite nanocrystallites. The crystal fringes marked A and B can be indexed to the (104) planes of magnesium calcite. The arrows mark pale contrasted regions where biological molecules are thought to be embedded. (d) Low magnification SEM image of a magnesium calcite particle. The square marks a hole in the surface whilst an arrow marks short aragonite microrods protruding from the surface. (e) High resolution SEM image of a hole in the surface of a magnesium calcite particle showing the early stage growth of aragonite microrods. The clusters marked by arrows are probably early stage aggregates of aragonite nanoparticles. Individual rod-shaped particles appear nearby. (f) SEM image of larger aragonite microrods protruding from a hole in the surface region of a magnesium calcite particle.

High resolution SEM and TEM images of magnesium-containing calcite and aragonite were used to understand the relation between these two phases. The SEM image of the surface of a Mg-calcite rhombohedral particle in Figure 4a shows their highly porous structure is constructed from small particles with a dimension in the range of 50-200 nm. Pores refer to the nanometer and sub-nanometer regions between the calcite nanocrystallites. Such aggregation of nanocrystallites was often found in the early stage crystal growth of zeolites and perovskites when some organic molecules were used as a structure directing agent. These aggregates of synthetic specimens normally undergo surface re-crystallisation into a single crystalline shell (Chen et al. 2007; Yang et al. 2010). However, in the natural travertine sample, we did not observe any surface re-crystallisation on the magnesium calcite particles. Some smooth domains as indicated by an arrow in Figure 4a are likely EPS molecules. The rhombohedral Mg-calcite particles are expected to contain several weight 
percent of embedded EPS molecules. This value cannot be accurately obtained as the organic matter is not evenly distributed, for example, regions such as the biofilm (Figure 5) and the dark coloured bands contain a significantly higher organic content. Although EPS primarily consists of carbon and oxygen it has been reported to contain small concentrations of calcium, phosphorous, sulphur, manganese, and iron (Allen et al. 2000). TEM (Figure 4b) of Mg-calcite rhombohedral particles detected nanoparticles with dimensions in the range of 10 to $50 \mathrm{~nm}$. This value is consistent with the measurement from the XRD results obtained using the Scherrer equation. It is implied that the particles of $50-200 \mathrm{~nm}$ in the SEM image in Figure 4a are not single crystalline, but contain many smaller crystallites. In fact, the contrast and the lattice fringes in Figure $4 \mathbf{c}$ suggests the larger nanoparticle consists of many domains with a size of 5-7 nm separated by lightly contrasted regions (marked by arrows) where EPS and other biomolecules are thought to be embedded. D-spacings measured from the crystal fringes marked A and B of separate crystallites in Figure 4c are $3.10 \AA$ and $3.06 \AA$, which can both be indexed to the (104) crystal plane of magnesium calcite. It is interesting to note that there is some distortion between the lattice fringes in the individual nanocrystallites (see the particle in Figure 4c), indicating they are not all perfectly oriented.

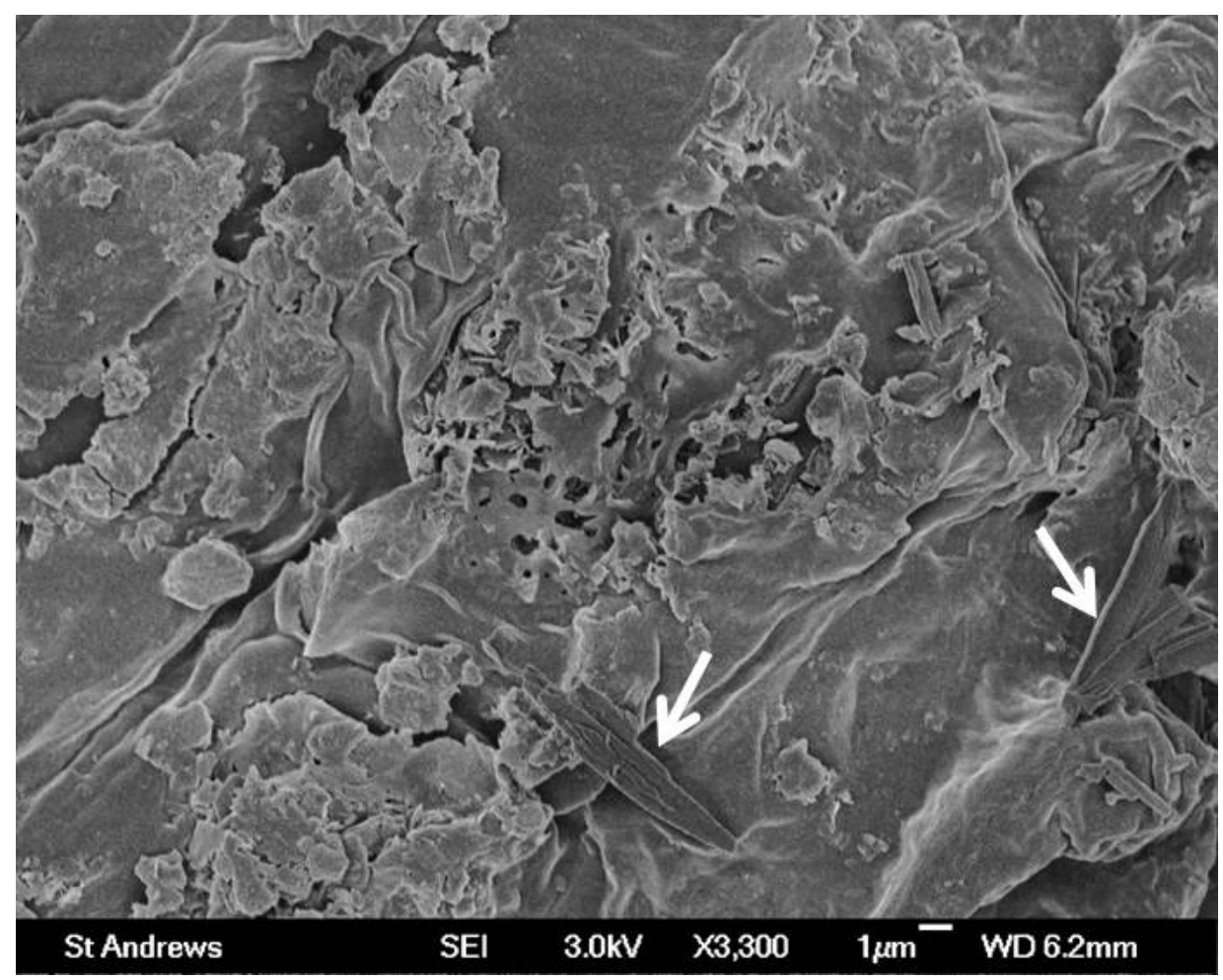

Figure 5: Low magnification SEM image of the microbial biofilm. Some aragonite particles are marked by arrows. 


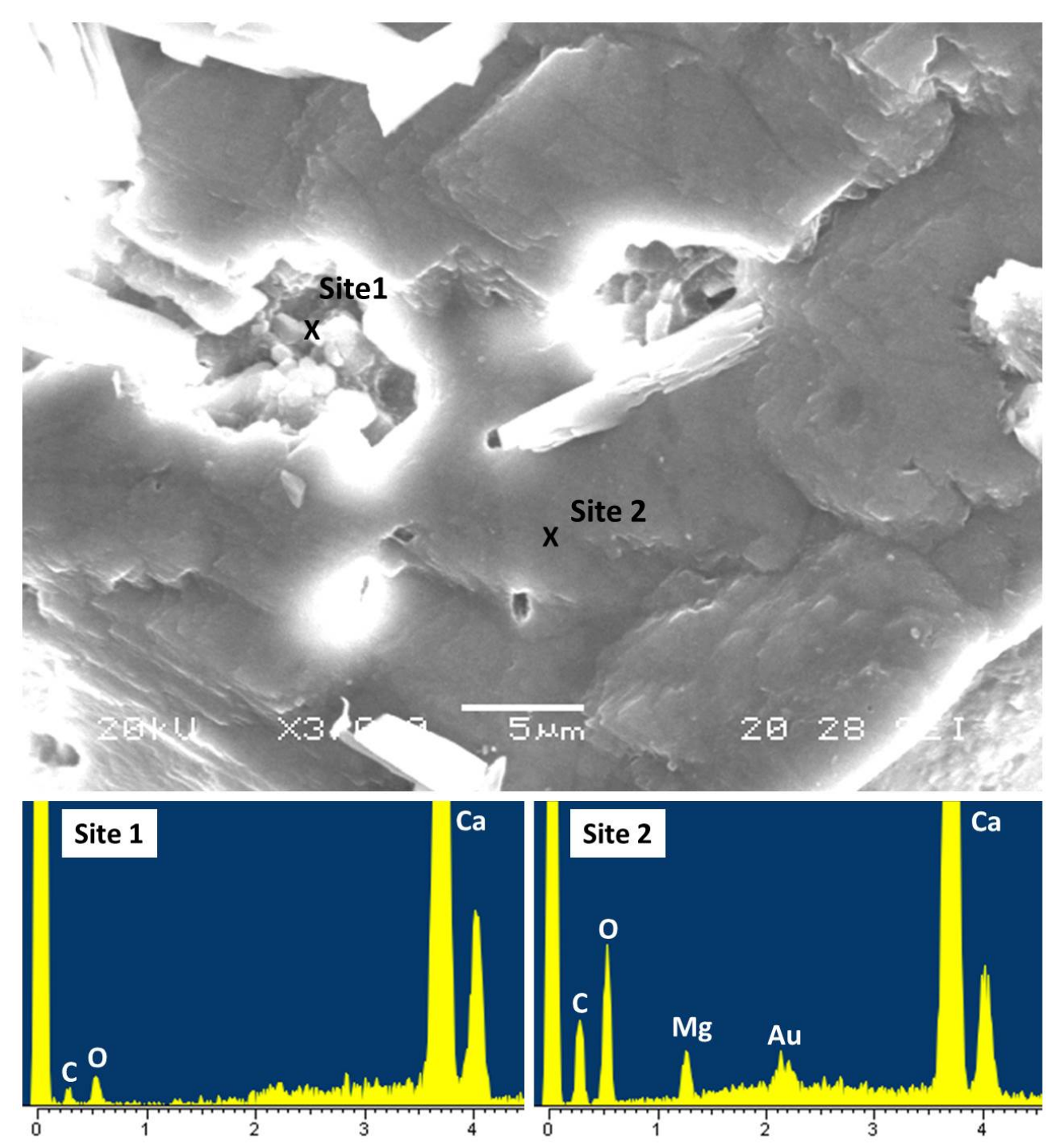

Figure 6. SEM image of the surface of a magnesium calcite particle containing several holes in the surface. EDX spectra were recorded from the two different marked sites on the particle.

Many rhombohedral particles were found to have holes in their surface as shown by the square in Figure 4d. Relatively short and thin aragonite microrods, as marked by an arrow in Figure 4d were found to protrude from the surface of some rhombohedral Mg-calcite particles although most of the Mg-calcite particles remained intact. The high resolution SEM image in Figure 4e recorded from a similar hole in the surface of a Mg-calcite particle shows a short aragonite microrod and several clusters of nanoparticles (marked by arrows). These clusters are very likely aragonite and demonstrate the stage at which $\mathrm{Mg}$-calcite underwent a phase transformation to aragonite but before the formation of aragonite microrods. The phase transformation from low crystallinity calcite to high crystallinity aragonite is accompanied by an increase in density and therefore is probably the main reason for the formation of the holes. This implies the nucleation of aragonite occurs inside the rhombohedral particle rather 
than on the surface. This was further confirmed by performing EDX on various different locations on a Mg-calcite particle containing several holes. The EDX spectra and corresponding SEM image in Figure 6 confirms that $\mathrm{Ca}, \mathrm{C}$ and $\mathrm{O}$, typical of aragonite could be detected in the holes whilst $\mathrm{Mg}, \mathrm{Ca}, \mathrm{C}$ and $\mathrm{O}$, typical of $\mathrm{Mg}$-calcite was present in the surface of the rhombohedral particle.

The SEM image in Figure 4f indicates that when the aragonite microrods in the core increased in size the surface of the rhombohedral Mg-calcite particle fractured and the particle became irregularly shaped. The aragonite microrods grew larger at the expense of the $\mathrm{Mg}$-calcite nanocrystallites and therefore the $\mathrm{Mg}$-calcite particle reduced in size and was located in the centre of an aragonite sheaf of rods (Figure 7a). Further growth of the aragonite microrods consumed all Mg-calcite nanoparticles to result in sheaf- like clusters of pure aragonite rods as shown in Figure 3c. The SEM image of aragonite rods in Figure $\mathbf{7 b}$ shows each of the rods has a relatively smooth surface and is composed of several needles.
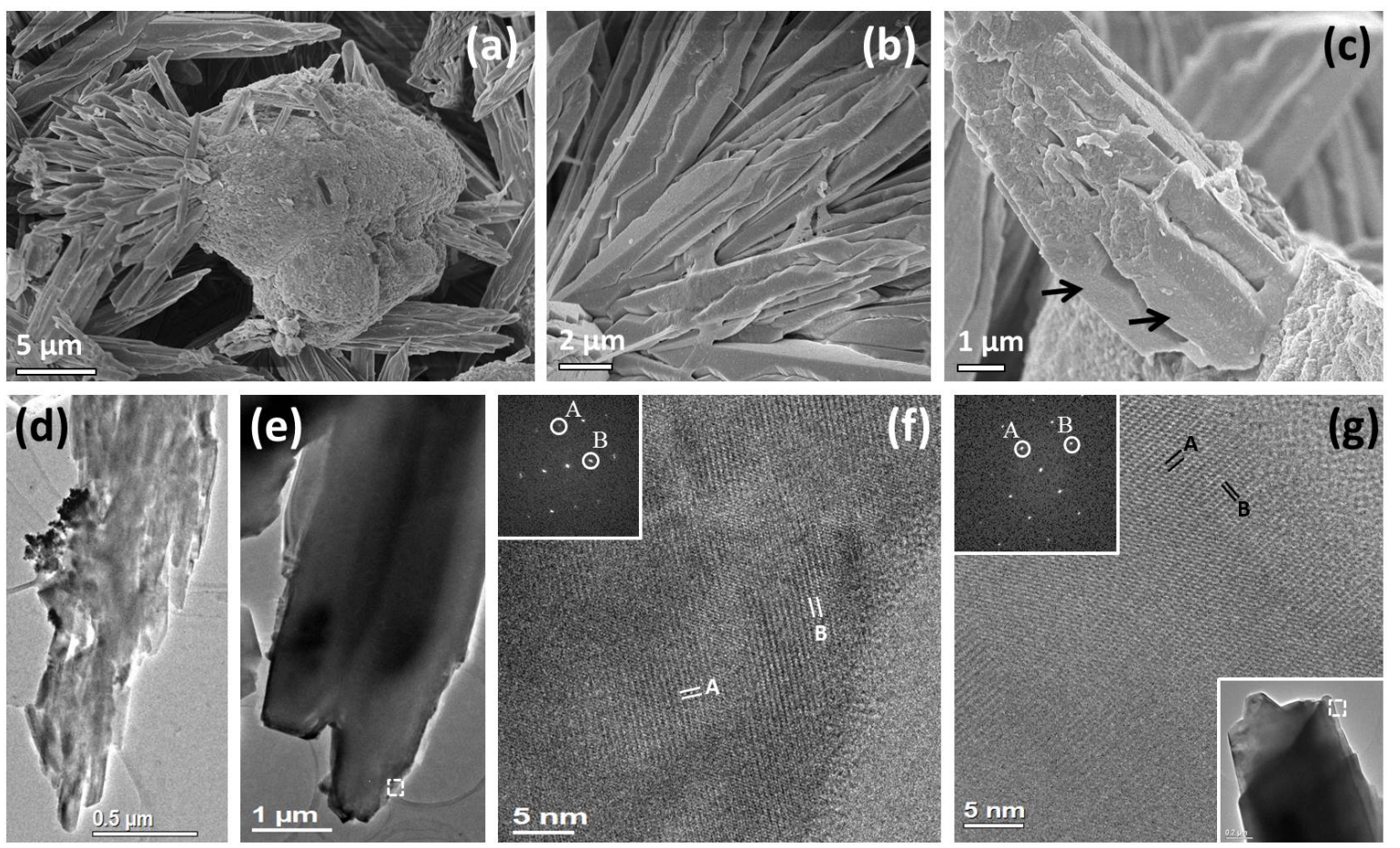

Figure 7. (a) SEM image of a magnesium calcite particle located in the centre of a sheaf of aragonite microrods. (b) High magnification SEM image of aragonite microrods. (c) SEM image of a fractured aragonite microrod. The arrows mark separate needles within the microrod which have same terminal surfaces and therefore appear to be orientated. (d) Low magnification TEM image of an aragonite needle composed of separate nanorods. (e) Low magnification TEM image of an aragonite rod with a higher density than (d). (f) HRTEM image recorded from the region marked by a square in (e). The lattice fringes indicate a domain structure whilst the corresponding FFT pattern (inset) confirms the domains have a uniform orientation. The fringes marked A $(2.87 \AA)$ and B $(4.86 \AA)$ can be indexed to the (002) and (100) planes of aragonite. (g) HRTEM image recorded from the aragonite microrod shown in the lower inset. The single crystal lattice fringes marked A and B correspond to the (001) and (020) planes of aragonite. The insets are the corresponding FFT pattern (top) and low magnification TEM image (bottom) indicating the region where the HRTEM image was recorded. 
The rough cross section of the fractured aragonite rod in Figure 7c shows that each of the needles is not a single crystal but is composed of many nanocrystallites. A smooth surface of the needles and same terminal surfaces as indicated by arrows suggests each of the needles within the rods have a uniform orientation. Zhou et al. (2009) observed a similar single crystal-like structure in 3-dimensionally oriented aragonite mesorods prepared in the absence of bio- or organic macromolecules. These mesorods with a length of several tens of microns consisted of many microrods perfectly aligned end-to-end and side-to-side. It was speculated that the long range dipole-dipole interactions between the aragonite microrods were responsible for their assembly into large mesorods with a perfect single crystal-like property. Low magnification TEM images of aragonite rods discovered that some rods are composed of many smaller needles with dimensions in the range of 40-50 nm by $400-500 \mathrm{~nm}$ (Figure 7d) whilst others gave the impression they are a single rod and likely a perfect single crystal (Figure 7e). HRTEM images (Figure 7(f,g)) revealed that the nanostructure of the aragonite microrods can vary greatly. The HRTEM image in Figure 7f shows the aragonite microrod consists of many nanodomains (10-20 nm in size), likely separated by embedded EPS molecules. The marked lattice fringes of A $(2.87 \AA)$ and B $(4.86 \AA)$ with an interplane angle of $90^{\circ}$ can be indexed to the (002) and (100) crystal planes of aragonite. The Fast Fourier Transform (FFT) pattern shown inset displaying a single crystal property confirms that all of these nanodomains are well orientated. Figure $6 \mathrm{~g}$ is a HRTEM image recorded from a different aragonite microrod. With no visible nanodomains the crystallinity appears to be much higher compared to the microrod in Figure $6 \mathrm{f}$ so that it can be treated as a single crystal, although some local defects are still visible. The d-spacings marked A and B in Figure $6 \mathrm{~g}$ are $5.73 \AA$ and $4.11 \AA$ respectively, corresponding to the (001) and (020) aragonite crystal planes. Both HRTEM images also confirm the long dimension of the microrods is parallel to the c-axis of aragonite

\section{Discussion of Formation Mechanism}

Based on the electron microscopic investigation combined with the XRD and EDX analysis of particles in the travertine crust specimen a mechanism can be proposed for the phase transformation of polycrystalline rhombohedral Mg-calcite particles into sheaf-like clusters of aragonite rods. This phase transformation is coherent with the analysis of the specimens collected from several different regions along the profile direction. Using this sampling methodology the top layer is expected to be the youngest one and is underlaid by 
progressively older layers. SEM observation of the biofilm layer (Figure 5) is consistent with the proposed phase transformation from magnesium calcite to aragonite. This layer is the oldest layer and therefore only aragonite (marked by arrows in Figure 5) could be detected.

Even though the phase transformation from calcite to aragonite is not usually feasible due to the high stability of perfect single crystals of calcite, this story is different when calcite contains a large quantity of magnesium and when the particles are actually composites of nanocrystallites of $\mathrm{Mg}$-calcite and biomolecules. When the $\mathrm{Mg}$ : Ca ratio is low, magnesium can be incorporated into the calcite lattice. It is widely reported that when the concentration of magnesium is sufficiently high the growth of calcite can be poisoned since $\mathrm{Mg}^{2+}$ ions are much more strongly hydrated than $\mathrm{Ca}^{2+}$ ions and therefore are more strongly adsorbed onto the surface of calcite (Folk 1974). The binding of these ions to the active growth sites of calcite can impede any further growth or increase straining in the local crystal lattice and therefore increase the solubility of Mg-calcite compared to pure calcite (Nielsen et al. 2013). This would therefore render Mg-containing calcite as energetically less favourable. The solubility of calcite with a magnesium content greater than $4 \mathrm{~mol} \%$ is reported to steadily increase with increasing Mg content (Mackenzie et al. 1983). Magnesium calcite with a magnesium content larger than $12 \mathrm{~mol} \%$ is said to have a higher solubility than aragonite (Andersson et al. 2008).

Although calcite has a rhombohedral unit cell and aragonite is orthorhombic, both structures consist of separate alternating layers of $\mathrm{Ca}^{2+}$ ions and $\mathrm{CO}_{3}{ }^{2-}$ ions perpendicular to the c-axis. Comparison of their crystal structures shows their Ca lattices are almost identical but the arrangement of $\mathrm{CO}_{3}{ }^{2-}$ ions is different. In aragonite, many of the $\mathrm{CO}_{3}{ }^{2-}$ ions are slightly tilted along the c-axis to create two distinct layers with a separation of $0.96 \AA$. The denser structure of aragonite compared to calcite means partially dehydrated magnesium ions cannot be incorporated into the crystal structure and therefore its growth cannot be inhibited (Loste et al. 2003). The formation of aragonite is favoured both thermodynamically and kinetically over calcite in the presence of a high magnesium concentration. In the present work, this was confirmed by EDX analysis where no Mg was detected in the aragonite rods.

In biogenic calcites the replacement of $\mathrm{Ca}^{2+}$ with divalent ions such as $\mathrm{Mg}^{2+}, \mathrm{Sr}^{2+}, \mathrm{Fe}^{2+}$ and $\mathrm{Mn}^{2+}$ is known to play an important role in the $\mathrm{CaCO}_{3}$ precipitation mechanism and polymorph selection despite their role being not completely understood. Magnesium calcite with magnesium contents ranging from a few percent to a maximum of $43.5 \mathrm{~mol} \%$ are a common occurrence in the teeth and skeletons of many echinoderms (Schroeder et al. 1969; Kroch and Nebelsick 2010). Raz et al. (2003) discovered that alongside matrix 
macromolecules, magnesium ions and are responsible for the formation and transient stabilisation of amorphous calcium carbonate (ACC) as a precursor phase of calcite in the spicules of a sea urchin. It was found that in the absence of $\mathrm{Mg}^{2+}$ ions in the solution, only calcite formed and the macromolecules alone where unable to mediate ACC in vitro. It was said that further investigations are required to clarify if interactions between the magnesium ions and the macromolecules increases the degree of supersaturation, thereby initiating the formation of metastable ACC.

The formation mechanism in the present work can be summarised by the six principle steps shown in Figure 8. It is thought that a microbial biofilm consisting of negatively charged EPS molecules induced the nucleation and precipitation of calcite nanocrystallites following the transfer of carbon dioxide from ground water highly charged with calcium and bicarbonate (Figure 8a). It is suggested that a combination of the incorporation of $\mathrm{Mg}^{2+}$ ions into the calcite lattice and the adsorption of EPS molecules on the surface of the early stage calcite crystallites restricted the size of the individual crystallites to the nanoscale and thus prevented their growth from following the classical crystal growth route (Figure 8b). According to the classical crystal growth theory established approximately 120 years ago a crystal forms from the nucleation and repeated attachment of atoms, molecules or ions to a single nucleus (Ostwald 1896). Therefore it is expected that the crystal size should increase according to time and that single crystals should exist at all growth stages. In the present case this did not occur. Instead, these calcite nanocrystallites/biological macromolecules underwent aggregation to generate highly porous rhombohedral shaped aggregates (Figure 8c). Despite the rhombohedral shape this polycrystalline morphology cannot be predicted by the Bravais-Friedel-Donnay-Harker (BFDH) law (Bravais 1866; Friedel 1907; Donnay and Harker 1937) and the Hartman-Perdok approach (Hartman and Perdok 1955) where the final crystal morphology is said to be dominated by slow-growing faces because the fast growing faces will grow out so are often not represented in the final morphology. On the other hand, formation of polyhedral morphology can be explained using the more general Curie-Wulff theorem where the equilibrium shape of a free crystal is that which minimises its surface free energy (Curie 1885; Wulff 1901). However, the Mg-calcite particles investigated in the present work are polycrystalline. It is not easy to explain the formation of their rhombohedral shape using the above two theories, a kinetic approach of BFDH and thermodynamic approach of the Curie-Wulff theorem. Although we are unable to fully understand the driving force of the morphology control, we can at least speculate two properties of the particles. One is that the nanocrystallites in the particles are self-orientated very well. The second is that the 
calculation of surface energy for these particles should consider the biomolecules as well as the crystals.

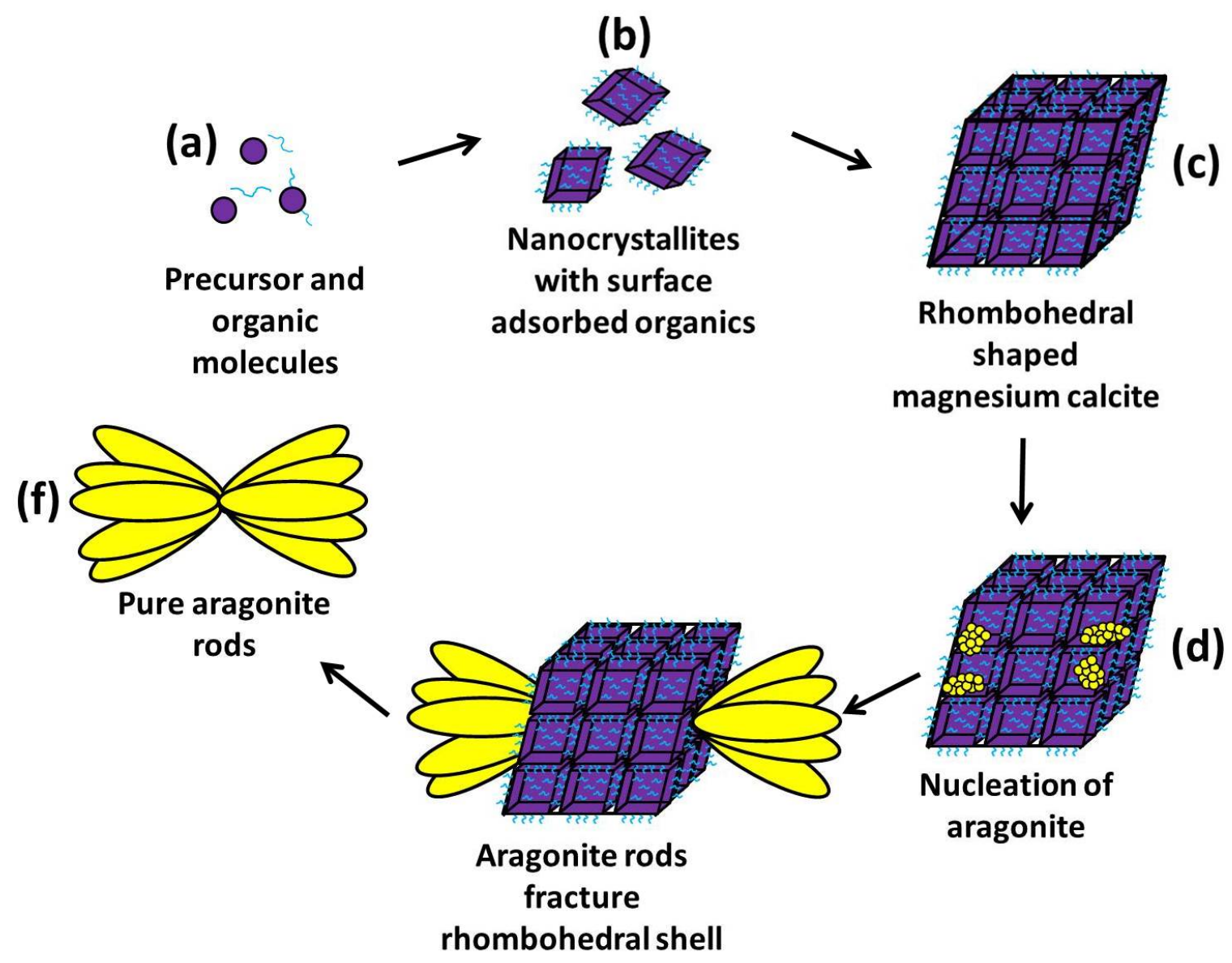

(e)

Figure 8: Schematic drawing of the proposed formation mechanism of the travertine crust specimen and the phase transformation from magnesium calcite to aragonite.

When the concentration of magnesium ions exceeded a certain point all further growth of calcite was prevented. Although a direct phase transformation from $\mathrm{Mg}$-calcite is deemed more likely at an early stage, an interface-coupled dissolution-reprecipitation mechanism, i.e. dissolution of $\mathrm{Mg}$-calcite followed by the re-crystallisation of aragonite, dominates the phase transformation process. The poisoning of calcite caused the nucleation of aragonite nanocrystallites beneath the surface of the rhombohedral particles (Figure 8d). These nanocrystallites, $c a \cdot 10-20 \mathrm{~nm}$ in size were able to assemble with a uniform orientation into microrods. The chemical composition, i.e. the concentrations of $\mathrm{Ca}^{2+}, \mathrm{HCO}_{3}{ }^{-}, \mathrm{Mg}^{2+}$ and biomolecules, as well as $\mathrm{pH}$ and temperature of the water may all affect the process. The monocrystalline-like aragonite rods with a higher density than Mg-calcite grew larger at the 
expense of the rhombohedral Mg-calcite nanocrystallites. The aragonite rods broke through the shell of the rhombohedral particles (Figure 8e) and finally when all the Mg-calcite nanocrystallites were completely consumed, sheaf-like clusters of pure aragonite rods resulted (Figure 8f). Finally, over a longer period of time the 10-20 nm sized aragonite domains fused together to generate a real single crystal. Despite the aragonite rods existing in a sheaf-like arrangement where each of the rods is further constructed from much smaller microrods they display perfect single crystal characteristics with the long axis of each rod parallel to the c-axis of aragonite.

\section{Conclusions}

In summary, we have proposed a new non-classical formation mechanism to explain the phase transformation from magnesium calcite to aragonite in a travertine crust specimen. Despite the common occurrence of this phase transformation in nature very few studies have been carried out to determine the step-by-step transformation from a morphology point of view. Instead, this phase transformation has mostly been studied in vitro to mimic biomineralisation (Loste et al. 2003; De Choudens-Sánchez and González 2009; Raz et al. 2000). In the present work, direct characterisation of a travertine crust specimen demonstrated that the nucleation of aragonite took place inside rather than on the surface of the rhombohedral polycrystalline Mg-calcite particles. Aragonite in the form of rods, with a higher density $\left(2.944 \mathrm{~g} / \mathrm{cm}^{3}\right)$ than calcite $\left(2.711 \mathrm{~g} / \mathrm{cm}^{3}\right)$ grew at the expense of the Mg-calcite nanocrystallites to form a pure aragonite phase consisting of a sheaf-like arrangement of single crystal aragonite rods. In this non-classical mechanism the combination of $\mathrm{Mg}^{2+}$ ions and EPS molecules are thought to play several important roles, such as controlling the crystal size to a nanometer scale and inducing aggregation in specimens. On the basis of the present work it is expected that a better understanding of the mechanistic study of natural occurring biominerals can assist in the designing of synthetic strategies. These biomimetic design principles are important for tailoring the properties of a material for a desired application.

\section{Acknowledgements}

HFG would like to thank the University of St Andrews for the studentship and Mr Ross Blackley for his help on using the SEM and TEM microscopes. WZZ thanks EPSRC for financial support on FEG-SEM equipment (EP/F019580/1) and a Platform (EP/K015540/1). 


\section{References}

Allen CC, Albert FG, Chafetz HS, Combie J, Graham CR, Kieft TL, Kivett SJ, McKay DS, Steele A, Taunton AE, Taylor MR, Thomas-Keprta KL, Westall F (2000)

Microscopic physical biomarkers in carbonate hot springs: implications in the search for life on mars. Icarus 147:49-67

Andersson AJ, Mackenzie FT, Bates NR (2008) Life on the margin: implications of ocean acidification on Mg-calcite, high latitude and cold-water marine calcifiers. Mar Ecol Prog Ser 373:265-273

Arp G, Reimer A, Reitner J (2001) Photosynthesis-induced biofilm calcification and calcium concentrations in phanerozoic oceans. Science 292:1701-1704

Atkins P, De Paula J (2010) Atkins' physical chemistry. $9^{\text {th }}$ Ed., Oxford

Bravais A (1866) Études Crystallographiques, Gauthier-Villars, Paris

Capezzuoli E, Gandin A, Pedley M (2014) Decoding tufa and travertine (fresh water carbonates) in the sedimentary record: the state of art. Sedimentology 61:1-21

Chen XY, Qiao MH, Xie SH, Fan KN, Zhou WZ, He HY (2007) Self-construction of coreshell and hollow zeolite analcime icositetradedral: a reversed crystal growth process via oriented aggregation of nanocrystallites and recrystallization from surface to core. J Am Chem Soc 129:13305-13312

Curie P (1885) Sur la formation des cristaux et sur les constants capillaires de leurdifférentes faces. Bull Soc Fr Mineral Cristallogr 8:145-150

De Choudens-Sánchez V, González LA (2009) Calcite and aragonite precipitation under controlled instantaneous supersaturation: elucidating the role of $\mathrm{CaCO}_{3}$ saturation state and $\mathrm{Mg} / \mathrm{Ca}$ ration on calcium carbonate polymorphism. J Sediment Res 79:363376

Donnay JDH, Harker D (1937) A new law of crystal morphology extending the law of Bravis. Am Mineral 22:446-467

Folk RL (1974) The natural history of crystalline calcium carbonate; effect of magnesium content and salinity. J Sediment Res 44:40-53

Friedel MG (1907) Étudessurla loi de bravais. Bull Soc Fr Mineral Cristallogr 30:326-455

Hacker BR, Kirby SH, Bohlen SR (1992) Time and metamorphic petrology: calcite to aragonite experiments. Science 258:110-112

Hacker BR, Rubie DC, Kirby SH, Bohlen SR (2005) The calcite $\rightarrow$ aragonite transformation in low-Mg marble: equilibrium relations, transformation mechansims, and rates. $\mathrm{J}$ Geophys Res-Sol 110:B03205 
Han YS, Hadiko G, Fuji M, Takahashi M (2006) Crystallization and transformation of vaterite at controlled pH. J Cryst Growth 289:269-274

Hartman P, Perdok WG (1955) On the relations between structure and morphology of crystals. II. Acta Crystallogr 8:521-524

Jin D, Wang F, Yue L (2011) Phase and morphology evolution of vaterite crystals in water/ethanol binary solvent. Cryst Res Technol 46:140-144

Jones B, Renaut RW (2008) Cyclic development of large, complex, calcite dendrite crystals in the Clinton travertine, interior British Columbia, Canada. Sediment Geol 203:1735

Kawano J, Shimobayashi N, Miyake A, Kitamura M (2009) Precipitation diagram of calcium carbonate polymorphs: its construction and significance. J Phys: Condens Matter $21: 425102-425107$

Kroch A, Nebelsick JH (2010) Echinoderms and oligo-miocene carbonate systems: potential applications in sedimentology and environmental reconstruction. Int Assoc Sedimentol Spec Publ 42:201-228

Lin S-J, Huang W-L (2004) Polycrystalline calcite to aragonite transformation kinetics: experiments in synthetic systems. Contrib Mineral Petrol 147:604-614

Loste E, Wilson RM, Seshadri R, Meldrum FC (2003) The role of magnesium in stabilising amorphous calcium carbonate and controlling calcite morphologies. J Cryst Growth 254:206-218

Mackenzie FT, Bischoff WD, Bishop FC, Loijens M, Schoonmaker J, Wollast R (1983) Magnesium calcites; low temperature occurrence, solubility and solid state behaviour. Rev Mineral Geochem 11:97-144

Nielsen LC, De Yoreo JJ, DePaolo DJ (2013) General model for calcite growth kinetics in the presence of impurity ions. Geochim Cosmochim Acta 115:100-114

Ostwald W (1896) Lehrbuch der Allgemeinen Chemie. W. Engelmann, Leipzig, Germany, Vol. 2, Part 1

Pentecost A (1985) Association of cyanobacteria with tufu deposits: identity, enumeration and nature of the sheath material revealed by histochemistry. Geomicrobiol J 4:285298

Pentecost A (2005) Travertine. Springer, The Netherlands 
Perdikouri C, Piazolo S, Kasioptas A, Schmidt BC (2013) Hydrothermal replacement of aragonite by calcite: interplay between replacement, fracturing and growth. Eur. J. Mineral. 25:123-136.

Plee K, Ariztegui D, Martini R, Davaud E (2008) Unravelling the microbial role in ooid formation - results of an in situ experiment in modern freshwater Lake Geneva in Switzerland. Geobiology 6:341-350

Raz S, Hamilton PC, Wilt FH, Weiner S, Addadi L (2003) The transient phase of amorphous calcium carbonate in sea urchin larval spicules: the involvement of proteins and magnesium ions in its formation and stabilization. Adv Funct Mater 13:480-486

Raz S, Weiner S, Addadi L (2000) Formation of high-magnesian calcites via an amorphous precursor phase: possible biological implications. Adv Mater 12:38-42

Ruan X, Li L, Liu J (2013) Flocculating characteristic of activated sludge flocs: interaction btween $\mathrm{Al}^{3+}$ and extracellular substances (EPS) J Environ Sci 25: 916-924

Schroeder JH, Dwornik EJ, Papike JJ (1969) Primary protodolomite in echinoid skeletons. Geol Soc Am Bull 80:1613-1616

Vu B, Chen M, Crawford RJ, Ivanova EP (2009) Bacterial extracellular polysaccharides involved in biofilm formation. Molecules 14:2535-2554

Wulff G (1901) Zur frage der geschwindigkeit des wachstums und der auflösung der kristallflächen. Z Kristallogr 34:449-530

Yang XF, Fu JX, Jin CJ, Chen J, Liang CL, Wu MM, Zhou WZ (2010) Formation mechanism of $\mathrm{CaTiO}_{3}$ hollow crystals with different microstructures. J Am Chem Soc 132:14279-14287

Yuan D, Wang Y (2013) Effects of solution conditions on the physicochemical properties of stratification components of extracellular polymeric substances in anaerobic digested sludge. J Environ Sci 25: 155-162

Zhou G-T, Yao Q-Z, Ni J, Jin G (2009) Formation of aragonite mesocrystals and implication for biomineralization. Amer Mineral 94:293-302 